\title{
Correlating charge transport to structure in deconstructed diketopyrrolopyrrole oligomers: A case study of a monomer in field-effect transistors
}

Pickett, Alec; Torkkeli, Mika; Mukhopadhyay, Tushita; Puttaraju, Boregowda; Laudari, Amrit; Lauritzen, Andreas; Bikondoa, Oier; Kjelstrup-Hansen, Jakob; Knaapila, Matti; Patil, Satish

Total number of authors:

11

Published in:

A C S Applied Materials and Interfaces

Link to article, DOI:

10.1021/acsami.8b04711

Publication date:

2018

Document Version

Peer reviewed version

Link back to DTU Orbit

Citation (APA):

Pickett, A., Torkkeli, M., Mukhopadhyay, T., Puttaraju, B., Laudari, A., Lauritzen, A., Bikondoa, O., KjelstrupHansen, J., Knaapila, M., Patil, S., \& Guha, S. (2018). Correlating charge transport to structure in deconstructed diketopyrrolopyrrole oligomers: A case study of a monomer in field-effect transistors. A C S Applied Materials and Interfaces, 10(23), 19844-19852. https://doi.org/10.1021/acsami.8b04711

\section{General rights}

Copyright and moral rights for the publications made accessible in the public portal are retained by the authors and/or other copyright owners and it is a condition of accessing publications that users recognise and abide by the legal requirements associated with these rights.

- Users may download and print one copy of any publication from the public portal for the purpose of private study or research.

- You may not further distribute the material or use it for any profit-making activity or commercial gain

- You may freely distribute the URL identifying the publication in the public portal 


\section{Organic Electronic Devices}

Subscriber access provided by DTU Library

\section{Correlating charge transport to structure in deconstructed diketopyrrolopyrrole oligomers: A case study of a monomer in field-effect transistors}

Alec Pickett, Mika Torkkeli, Tushita Mukhopadhyay, Boregowda Puttaraju, Amrit Laudari, Andreas

Lauritzen, Oier Bikondoa, Jakob Kjelstrup-Hansen, Matti Knaapila, Satish Patil, and Suchismita Guha

ACS Appl. Mater. Interfaces, Just Accepted Manuscript • DOI: 10.1021/acsami.8b04711 • Publication Date (Web): 17 May 2018

Downloaded from http://pubs.acs.org on May 22, 2018

\section{Just Accepted}

"Just Accepted" manuscripts have been peer-reviewed and accepted for publication. They are posted online prior to technical editing, formatting for publication and author proofing. The American Chemical Society provides "Just Accepted" as a service to the research community to expedite the dissemination of scientific material as soon as possible after acceptance. "Just Accepted" manuscripts appear in full in PDF format accompanied by an HTML abstract. "Just Accepted" manuscripts have been fully peer reviewed, but should not be considered the official version of record. They are citable by the Digital Object Identifier (DOI®). "Just Accepted" is an optional service offered to authors. Therefore, the "Just Accepted" Web site may not include all articles that will be published in the journal. After a manuscript is technically edited and formatted, it will be removed from the "Just Accepted" Web site and published as an ASAP article. Note that technical editing may introduce minor changes to the manuscript text and/or graphics which could affect content, and all legal disclaimers and ethical guidelines that apply to the journal pertain. ACS cannot be held responsible for errors or consequences arising from the use of information contained in these "Just Accepted" manuscripts. 


\title{
Correlating charge transport to structure in
}

\section{deconstructed diketopyrrolopyrrole oligomers: A}

\section{case study of a monomer in field-effect transistors}

\author{
Alec Pickett ${ }^{1}$, Mika Torkkeli ${ }^{2}$, Tushita Mukhopadhyay ${ }^{3}$, Boregowda Puttaraju ${ }^{3}$, Amrit Laudari, ${ }^{1}$ \\ Andreas E. Lauritzen, ${ }^{2,4}$, Oier Bikondoa ${ }^{5}$, Jakob Kjelstrup-Hansen ${ }^{6}$, Matti Knaapila ${ }^{2 \$}$, Satish \\ Patil $^{3}$, and Suchismita Guha ${ }^{1 *}$ \\ ${ }^{1}$ Department of Physics and Astronomy, University of Missouri, Columbia, MO 65211, USA \\ ${ }^{2}$ Department of Physics, Technical University of Denmark, 2800 Kgs. Lyngby, Denmark \\ ${ }^{3}$ Solid State and Structural Chemistry Unit, Indian Institute of Science, Bangalore 560012, India \\ ${ }^{4}$ Department of Physics, University of Oxford, OX13PU Oxford, UK \\ ${ }^{5}$ Department of Physics, University of Warwick. Gibbet Hill Road. CV4 7AL Coventry, UK \\ ${ }^{6}$ NanoSYD, Mads Clausen Institute, University of Southern Denmark, 6400 Sønderborg, \\ Denmark \\ KEYWORDS Conjugated molecules, Grazing incidence X-ray diffraction, Field-effect \\ transistors, Charge transport, Polymorphism
}


ABSTRACT. Copolymers based on diketopyrrolopyrrole (DPP) cores have attracted a lot of attention due to their high $p$-type as well as $n$-type carrier mobilities in organic field-effect transistors (FETs) and high power conversion efficiencies in solar cell structures. We report the structural and charge transport properties of $n$-dialkyl side-chain substituted thiophene DPP endcapped with a phenyl group (Ph-TDPP-Ph) monomer in FETs which were fabricated by vacuum deposition and solvent coating. Grazing incidence X-ray diffraction (GIXRD) from bottom-gate, bottom-contact FET architectures were measured with and without biasing. $\mathrm{Ph}$-TDPP-Ph reveals polymorphic structure with $\pi$-conjugated stacking direction oriented in-plane. The unit cell comprises either one monomer with $a=20.89 \AA, b=13.02 \AA, c=5.85 \AA, \alpha=101.4^{\circ}, \beta=90.6^{\circ}$, and $\gamma=94.7^{\circ}$ for one phase (TR1), or two monomers with $a=24.92 \AA, b=25.59 \AA, c=5.42 \AA, \alpha=80.3^{\circ}$, $\beta=83.5^{\circ}$, and $\gamma=111.8^{\circ}$ for the second phase (TR2). The TR2 phase thus signals a shift from a coplanar to herringbone orientation of the molecules. The device performance is sensitive to the ratio of the two triclinic phases found in the film. Some of the best FET performances with $p$ type carrier mobilities of $0.1 \mathrm{~cm}^{2} / \mathrm{Vs}$ and on/off ratio of $10^{6}$ are for films that comprise mainly the TR1 phase. GIXRD from in-operando FETs demonstrates the crystalline stability of PhTDPP-Ph. 


\section{INTRODUCTION}

The design of systems incorporating both donor and acceptor chromophores in a polymer or oligomer are of interest in ambipolar organic field-effect transistors (FETs) and solar cells. Conjugated oligomers and polymers based on donor-acceptor (D-A) moieties may be tuned such that their bandgap energies are lowered. Such low bandgap materials are not just useful for device applications but are desired to achieve chemically stable organic semiconductors. The strong intermolecular interactions may lead to molecular packing with a large electronic bandwidth, enhancing charge carrier mobilities. Copolymers of diketopyrrolopyrrole (DPP) have attracted a lot of attention due to their high carrier mobilities and stable performance in organic FETs and solar cells. ${ }^{1-10}$ The tuning of the optical bandgap of DPP copolymers, for example, allows application in near-infrared hybrid photodetectors. ${ }^{11}$ Some approaches for improving carrier mobility in DPP-based copolymers, where the DPP unit acts as an acceptor, are side-chain engineering, ${ }^{12}$ incorporating planar end groups, ${ }^{13}$ and designing polymers by coupling two DPP core units to control the $\pi$-orbital delocalization. Copolymers based on coupled DPP-DPP units have resulted in high mobility $n$-channel FETs. ${ }^{1,7}$ There are also reports of organometallic DPP core based systems, with the triplet excitonic states playing a role in the photovoltaic process; such systems have a potential impact in optoelectronics by tailoring the cyclomettalating ligands. ${ }^{14}$

Due to the inherent dispersity imposed by synthetic routes in conjugated polymers, correlating molecular structure to device performance often remains a challenge. This poses additional barriers in obtaining an in-depth structure-property relationship in D-A polymers where the crystallinity and packing of the molecules are strongly related to chain folding and chain length. 
In a recent work by Mukhopadhyay et al. chain length studies of DPP oligomers were conducted from one to five repeating units. ${ }^{15}$ These studies reveal the role of chain length to the transition between molecular packing to disordered polymer-type packing. Monodisperse oligomers thus provide a benchmark for correlating charge transport to crystal packing. Moreover, the method of deposition of organic molecules/oligomers to form thin films dictates crystal packing and charge transport properties. Altering the film growth, which can involve vacuum evaporation, spincoating, and other crystallization processes, along with tailoring the halogen interaction at the semiconductor-dielectric interface in FET architectures has been extensively used in soluble bis(triethylsilylethynyl)-anthradithiophene (TES-ADT)-type semiconductors to correlate carrier mobility with molecular packing and structure. ${ }^{16-17}$

Further, polymorphism plays a large role in governing crystal structure and consequently charge transport. ${ }^{18-21}$ By using compositionally identical but structurally different guest-host systems based on TES-ADTs, it was shown that FET carrier mobilities are greatly reduced by adding the syn isomer to anti TES-ADT. ${ }^{22}$ By considering non-covalent interactions, quantum chemical investigations from isomers of functionalized oligoacenes highlight the mechanism of enhanced charge transport properties in "brickwork" configuration compared to "slipped-stack" structures. $^{23}$ Such stacking configurations have been observed in molecular crystals based on dibenzo-chrysene; the slipped-stack configuration yields FET charge carrier mobilities almost two orders of magnitude lower than the brickwork configuration. ${ }^{24}$

Another question that arises in determining FET performance and stability is whether there are any structural changes to the organic semiconductor upon the application of a gate voltage or bias stress in-operando. Changes to the threshold voltage under prolonged electrical bias in FETs have been attributed to trapping and migration of charges, ${ }^{25-27}$ although the exact mechanism 
remains unclear. Surface-enhanced Raman scattering from pentacene FETs reveal disorder incorporated by $s p^{3}$ carbons, which disrupt the aromaticity of the molecule, upon application of a bias stress; ${ }^{28}$ such a disorder was not observed in low operating voltage pentacene FETs. ${ }^{29}$ Liscio and coworkers employed grazing-incidence X-ray diffraction (GIXRD) from biased pentacene FETs, and proposed that an applied electric field could reorient a fraction of the pentacene molecules located at or near grain boundaries. ${ }^{30}$ These experimental observations in pentacene raise further questions as to whether structural changes under applied electric fields in FETs may occur in other small molecules that show a herringbone pattern. In particular, how robust are DPP based oligomers structurally upon bias stress and do their processing condition impact transport properties?

Huss-Hansen and co-workers measured GIXRD from biased small molecule 5,5'-bis(naphth-2yl)-2,20-bithiophene $\left(\mathrm{NaT}_{2}\right)$ FETs, and by varying the gate voltage over a $10 \mathrm{~h}$ period find effectively no changes to its structure refinement, demonstrating the crystalline stability of the system under operation. ${ }^{31}$ GIXRD is a useful tool not just for revealing the structure and molecular packing of thin organic films but is also becoming an accessible technique for studying structural properties from working devices to correlate changes in transport properties to structural properties of organic semiconductors.

In this work we focus on a monodisperse small molecule of $n$-dialkyl side-chain substituted thiophene DPP end-capped with a phenyl group ( $\mathrm{Ph}$-TDPP-Ph). The alkyl side chain facilitates solution processing. Both evaporated and solution processed films were used in FETs, where the dropcast films were fabricated using solvents with different boiling points. GIXRD from the PhTDPP-Ph films reveals two distinct triclinic phases either with one or two molecules per unit cell. The two phases are interpreted in terms of the differences in the inclination of the molecule 
plane from the $c$-axis. The ratio between these phases depends to some extent on processing conditions, and further dictates the transport properties in FETs. Our study shows that a slight shift from a coplanar structure can hinder transport properties. The FET carrier mobilities are seen to change by few orders of magnitude depending on the ratio of the two triclinic phases. The highest FET carrier mobilities and improved on/off ratios are observed for Ph-TDPP-Ph films that have a low fraction of the triclinic phase with two monomers per unit cell. Contrary to other small molecules such as pentacene, where the herringbone packing promotes improved transport properties, the herringbone packing motif in $\mathrm{Ph}-\mathrm{TDPP}-\mathrm{Ph}$ is seen to be detrimental to carrier transport.

\section{EXPERIMENTAL METHODS}

\subsection{Monomer Synthesis}

Synthesis of 2,5-bis(2-octyldodecyl)-3,6-bis(5-phenylthiophen-2-yl)pyrrolo[3,4- c]pyrrole1,4(2H,5H)-dione (Ph-TDPP-Ph): To a mixture of phenyl boronic acid (0.079 g, $0.64 \mathrm{mmol})$, potassium carbonate $(0.089 \mathrm{~g}, 0.64 \mathrm{mmol})$ in toluene/ethanol $(3: 1,60 \mathrm{~mL})$, the reaction mixture was stirred at $50^{\circ} \mathrm{C}$ for $30 \mathrm{~min}$. Then the compound 3,6-bis(5-bromothiophen-2-yl)-2,5-bis(2octyldodecyl)pyrrolo[3,4-c]pyrrole-1,4(2H,5H)-dione (0.3 g, $0.29 \mathrm{mmol})$ was added one portion, and the reaction mixture was heated at $110^{\circ} \mathrm{C}$ for $12 \mathrm{~h}$ and then cooled to room temperature. Dichloromethane $(100 \mathrm{~mL})$, water $(200 \mathrm{~mL})$ were added and the layer separated. The organic layer was concentrated in-vacuиo. Further purification was carried out by column chromatography on silica gel eluting with hexane/ethyl acetate $(5 \%)$ to give compound $\mathrm{Ph}$ TDPP-Ph as a dark blue solid $(0.22 \mathrm{~g}, 75 \%)$. The chemical structure is shown in Figure 1 (a). The NMR and MALDI spectra of Ph-TDPP-Ph are provided in Figures S1-S3. 


\subsection{Materials}

The $\mathrm{Si}^{++} / \mathrm{SiO}_{2}$ substrates were purchased from Silicon Quest International. 1,2dichlorobenzene (anhydrous, 98\%), toluene (HPLC grade), and octadecyltrichlorosilane ( $\geq 90 \%)$ were procured from Sigma Aldrich, Inc. Chloroform (HPLC grade) was acquired from Fisher Scientific. The gold (Au wire, 99.99\%) used for electrode evaporation in the top-contact devices was obtained from Kurt J. Lesker Company.

\subsection{Substrate Preparation}

Top-contact substrates: $\mathrm{SiO}_{2}$ was cleaned thoroughly via organic cleaning and plasma cleaning. Substrates were sonicated in acetone and isopropanol for 10 minutes each, then rinsed with DI water after and dried with compressed nitrogen. After drying, the substrates were plasma cleaned for 10 minutes in a Harrick Plasma PDC-32G Plasma Cleaner at a chamber pressure of 300 mTorr of $\mathrm{O}_{2}$ gas. Some $\mathrm{SiO}_{2}$ substrates were also treated with an octadecyltrichlorosilane (OTS) monolayer. These substrates were first piranha cleaned by placing them in a 10:3.5 mL mixture of $\mathrm{H}_{2} \mathrm{SO}_{4}: \mathrm{H}_{2} \mathrm{O}_{2}$ for 10 minutes and then rinsed with DI water. 24 hours after piranha cleaning, $0.25 \mathrm{~g}$ of OTS was diluted in $10 \mathrm{~mL}$ of toluene and substrates were allowed to sit in solution up to 25 seconds.

Bottom-contact substrates: Highly n-doped silicon with $200 \mathrm{~nm}$ thermally grown $\mathrm{SiO}_{2}$ functioning as the gate dielectric was used as substrates for the bottom-contact devices. Interdigitated source-drain electrodes with $500 \mu \mathrm{m}$ spacing were patterned by photolithography and realized by metal evaporation $(3 \mathrm{~nm} \mathrm{Ti} / 30 \mathrm{~nm} \mathrm{Au})$ and lift-off. A second photolithography step was used to pattern gate electrode contact pads which were realized by HF etching, metal evaporation (3 nm TI/30 nm Au), and lift-off. This design (Figure 1(d)) fits into zero-insertion force (ZIF) sockets thereby enabling electrical biasing during GIXRD characterization. 


\subsection{Thin Film and FET Preparation}

The Ph-TDPP-Ph powder was transferred to a quartz crucible to be thermally evaporated in a vacuum vapor deposition chamber inside a nitrogen filled glovebox. The film thickness was monitored during evaporation by an Inficon quartz crystal monitor and later confirmed using a Veeco NT 9109 optical profilometer. For dropcast films, Ph-TDPP-Ph powder was dissolved in either anhydrous toluene or a mixture of 1,2-dichlorobenzene and chloroform $(1: 1 \mathrm{vol} \%)$ at a solute concentration of $10 \mathrm{mg} / \mathrm{mL}$ and let sit for at least 6 hours to properly dissolve. $\mathrm{SiO}_{2}$ substrates were heated to $60^{\circ} \mathrm{C}$ on a hot plate and held at angles $<10^{\circ}$ at which point less than $30 \mu \mathrm{L}$ of the Ph-TDPP-Ph solution was dropped onto the $\mathrm{SiO}_{2}$. The solution was allowed to run parallel to the direction of channel length, depositing a film as the solvent evaporated. Both topcontact and bottom-contact (with interdigitated electrodes) FETs were fabricated, as shown in Figures 1 (b) and (c). Immediately after film deposition, top $\mathrm{Au}$ contacts were thermally evaporated in a desired architecture via shadow masks. The chamber pressure during evaporation was $5 \times 10^{-5}$ mbar. The FET channel width $(\mathrm{W})$ to length $(\mathrm{L})$ ratios varied between $8-20$. GIXRD from in-operando studies were conducted from bottom-contact FETs with W/L ratio of 270.

\subsection{Electrical characterization and GIXRD Setup}

Electrical characterizations were performed using a Keithley 2400 and a Keithley 236 sourcemeter. The 2400 sourcemeter was used to apply the gate voltage and measure gate current while the 236 sourcemeter applied drain-source voltage and measured the drain current. All measurements were performed at room temperature under ambient conditions. Electrical biasing for in-operando GIXRD measurements was conducted with a Hewlett-Packard E3620A voltage source and a programmable Kepco BOP100-10MG voltage source, which were used to supply the gate and source-drain voltages, respectively, while the drain current was monitored by a 
Keithley 486 picoammeter. All measurements were performed in a dedicated sample chamber filled with helium.

The GIXRD measurements of Ph-TDPP-Ph thin films were carried out at the UK CRG beamline, XMaS (BM28), at the European Synchrotron Radiation Facility (ESRF) in Grenoble, France. The samples were measured in a nylon/metal-printed sample chamber continuously flushed with helium in order to reduce the absorption and scattering due to air. X-ray energy of $10 \mathrm{keV}$ and a beam size of $50 \mu \mathrm{m} \times 350 \mu \mathrm{m}$ (height $\times$ width) were used. The samples were mounted onto a custom made circuit board allowing electrical connections to a ZIF-socket, as previously described in section 2.3. The angle of incidence was optimized for each sample to maximize the intensity of the diffraction and was around $0.16^{\circ}$ for the thin film samples. The $\mathrm{X}$ ray footprint varied from sample to sample and was generally around 11 millimeters along the diagonally aligned electrodes. The X-ray intensity images were recorded with an MAR165 charge-coupled device (CCD) detector placed about $350 \mathrm{~mm}$ from the sample.

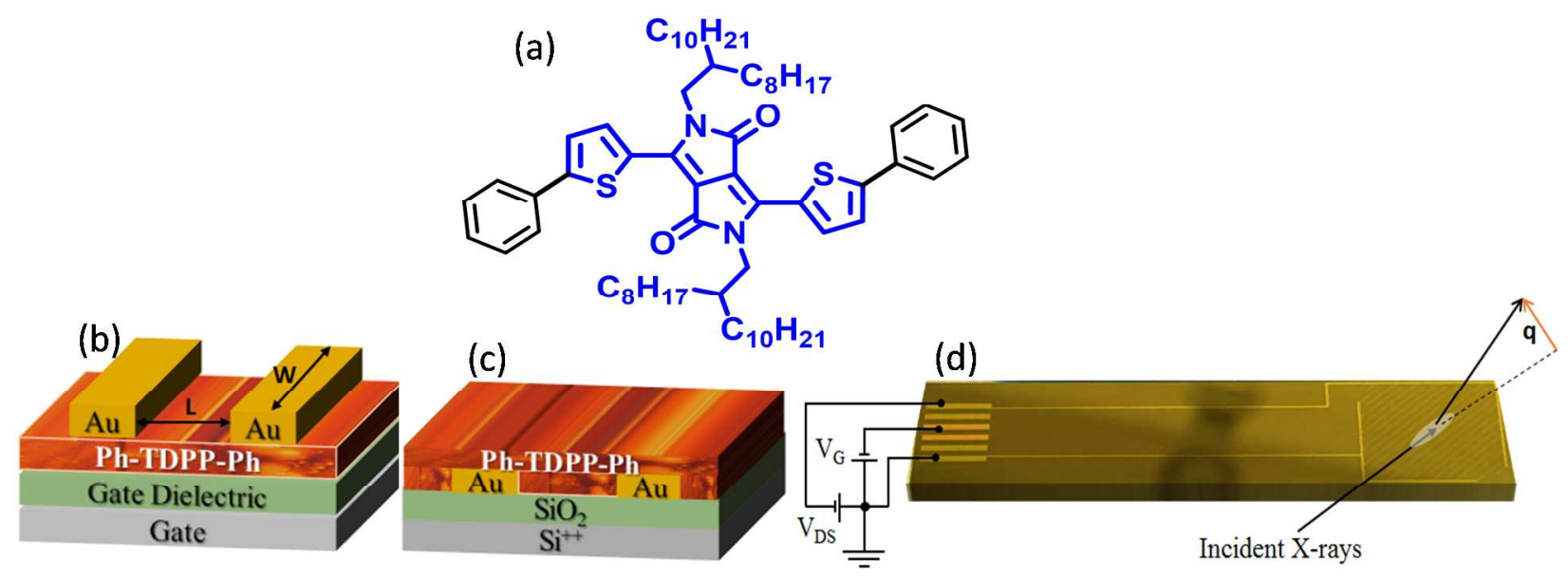

Figure 1. (a) Chemical structure of Ph-TDPP-Ph. Schematic of FET architectures for (b) topcontact, bottom gate and (c) bottom-contact, bottom-gate using Ph-TDPP-Ph as the 
semiconductor and $\mathrm{SiO}_{2}$ as the gate dielectric. (d) Image of the bottom-contact FET electrode layout used for GIXRD measurements.

\section{RESULTS AND DISCUSSIONS}

\subsection{GIXRD from Dropcast Films}

The Ph-TDPP-Ph films were developed for top-contact and bottom-contact, bottom-gate FETs via thermal evaporation and solution dropcasting. The structure was first solved for Ph-TDPP-Ph films on $\mathrm{SiO}_{2}$ dropcast from the mixture of dichlorobenzene and chloroform (DCB:Chl, 1:1 \% vol). The GIXRD measurements show a well aligned pattern of about 50 reflections, all of which can be indexed according to a triclinic unit cell of $a=20.89 \AA, b=13.02 \AA, c=5.85 \AA, \alpha=101.4^{\circ}$, $\beta=90.6^{\circ}$, and $\gamma=94.7^{\circ}$. The calculated density assuming one molecule per unit cell is $1.083 \mathrm{~g} / \mathrm{cm}^{3}$. The same diffraction pattern was observed for the corresponding samples deposited on glass. Figure 2 (a) shows examples of the indexed reflections where unit cell axes $b$ and $c$ are assumed to be on the horizontal $\left(q_{h}\right)$ plane. The calculated positions ( $h 00$ excluded) are shown with blue dots.

Other thick dropcast films (processed from DCB:Chl) were measured using a larger angle of incidence, which allowed a better angular resolution. These samples revealed a slightly different crystal structure, which is shown as a higher number of reflections, in particular at low angles. The samples showed weak alignment, but a thinner position on the film gave a diffraction pattern from which individual reflections could be indexed (Figure 2 (b)). Detailed study showed that we observe the same diffraction pattern as above for these dropcast films (shown in red); however, another crystalline structure appears which may be indexed in another triclinic unit cell with $a=24.92 \AA, b=25.59 \AA, c=5.42 \AA, \alpha=80.3^{\circ}, \beta=83.5^{\circ}$, and $\gamma=111.8^{\circ}$ (shown in blue). The calculated density assuming two molecules per unit cell is $1.084 \mathrm{~g} / \mathrm{cm}^{3}$. We shall refer to these 
two triclinic crystal morphologies with one and two molecules per unit cell as TR1 and TR2, respectively. Dropcast films $(<100 \mathrm{~nm})$ were entirely the TR1 phase as far as it could be observed (Figure 2(a)) whereas thicker films show both phases with a TR1:TR2 ratio of 20:1 (Figure 2(b)). The ratio of these two phases seems to vary with the solvent used. When a thick film is cast from toluene, the TR1:TR2 ratio is close to 1:4, as shown in the Supporting Information (Figure S4). In Section 3.2 we discuss how the phase ratio was determined.
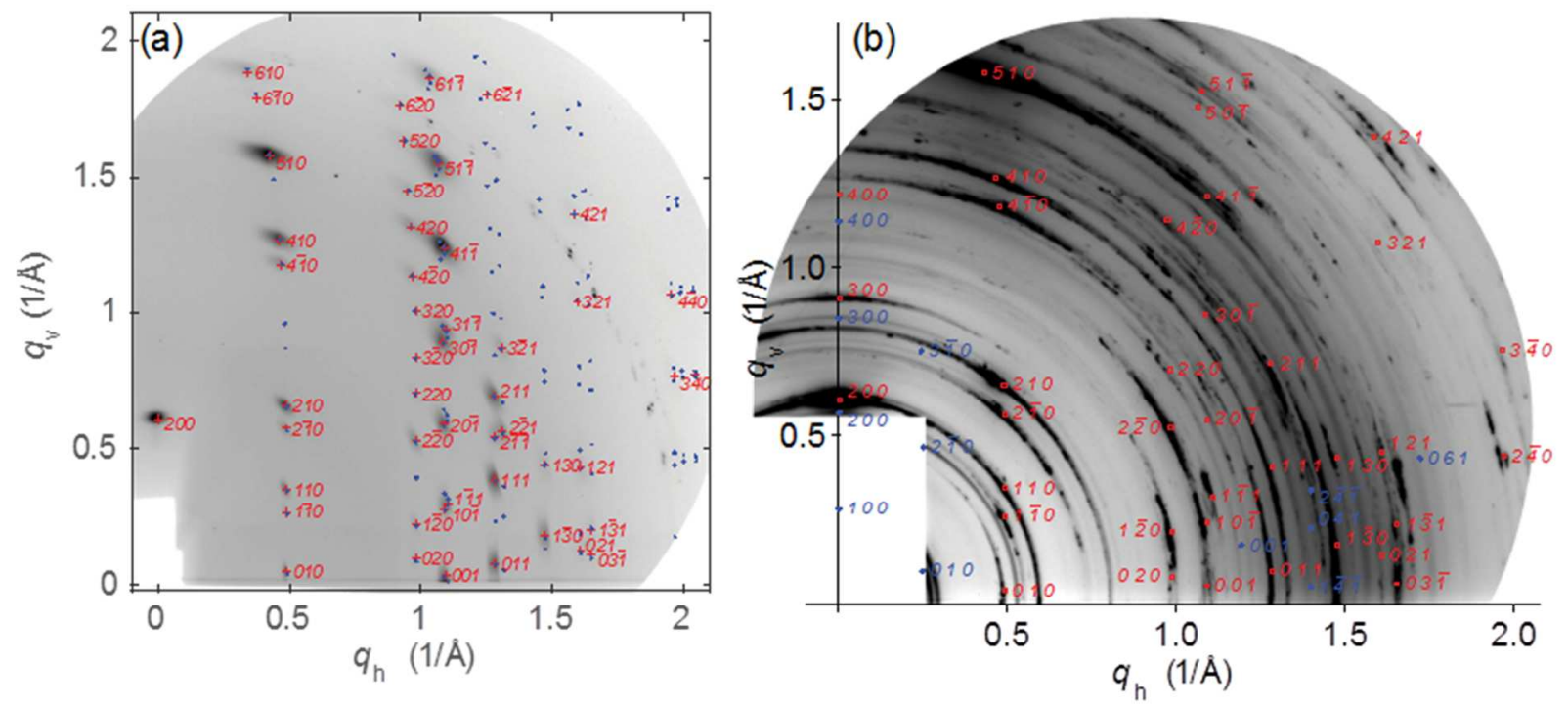

Figure 2. (a) GIXRD pattern of a thin $(<100 \mathrm{~nm}) \mathrm{Ph}$-TDPP-Ph film dropcast from a DCB:Chl solution on $\mathrm{SiO}_{2}$. The structure here has one molecule per unit cell with the crystalline form TR1. (b) GIXRD pattern of a thick (>100 nm) Ph-TDPP-Ph film dropcast from DCB:Chl. The image shows a weakly aligned and granular pattern of reflections that agree with the crystalline phase TR1 (indexed in red), but also very faint rings belonging to TR2 can be distinguished (blue).

Based on unit cell parameters and comparison between the two observed forms, we propose a general packing motif for the molecules. We note that despite differences in unit cell angles, the diffraction patterns have certain similarities. Both produce a strong layer line at exactly the same position $q_{h}=0.51 / \AA$ with asymmetric pairs of reflections, i.e., strong $h k 0$ and weak $h-k 0$ 
reflections. In particular, strong reflections 510 (TR1) or 6-20 (TR2) occur at about an $18^{\circ}$ angle from the surface. TR1 and TR2 show an approximate $13 \AA$ periodicity along the substrate surface, corresponding to the $q_{h}=0.51 / \AA$ layer line. The layer spacing normal to the surface increases from $20.9 \AA$ in TR1 to $24.9 \AA$ in TR2 while the $c$-axis spacing decreases from $5.85 \AA$ to $5.42 \AA$ and the unit cell density remains the same.

Therefore, we determine that the orientation of the molecule in the two structures is very similar with respect to the sample surface, while the changes in the $c$-axis indicate differences in the angle of inclination of the molecule plane from the $c$-axis, which we assume to be the direction of stacking. The inclination may occur by rotation around the molecule short axis (pitch) or the molecule long axis (roll), ${ }^{32}$ which generates translations along the long and short molecular axes. Essentially, this leads to a staggered coplanar geometry. Assuming the $\pi$ stacking distance to be $3.9 \AA$, the translations are $4.4 \AA$ (TR1) and $3.7 \AA$ (TR2) and the corresponding pitch and roll are $47^{\circ}$ and $42^{\circ}$, respectively from the cofacial $\pi$-stack. Due to the differences in the inclination of the molecules in the two triclinic phases (in the direction of stacking), we expect dramatic changes in charge transport properties between the two phases.

Detailed crystal data for the Ph-TDPP-Ph monomer studied here does not yet exist. A TDPP monomer with a shorter alkyl side group compared to the TDPP monomer here was investigated by Hartnett et al. ${ }^{33}$ and its crystal form was determined. The molecules are arranged in columnar stacks with $6.53 \AA$ periodicity and $3.59 \AA \pi$-stacking distances, resulting in a large translation of $5.45 \AA$ ( $3.34 \AA$ longitudinal and $4.32 \AA$ transverse) between closest molecules in the stacks. The columnar stacks are lined side-by-side by hydrogen bonding between thiophene 3-proton and carbonyl oxygen, which sets the inter-columnar distance to $10.2 \AA$. The hydrogen bonds may be responsible for the almost coplanar molecule orientation. ${ }^{33}$ 
Figure 3 plots our interpretation of the TR1 and TR2 phases in Ph-TDPP-Ph films. The columnar stacks occur in the $c$-direction with inter-columnar distance $13 \AA$. The observed $3 \AA$ period suggests hydrogen bonding between carbonyl oxygen and one or two of the phenyl hydrogens. The $a$-axis is assumed to be almost perpendicular to $c$-axis. In other words, the inclination is mostly by rolling the molecule about $50^{\circ}$ and therefore the translation is mostly transverse. The large transverse translation means that there is less $\pi$-stacking interaction within the columnar stacks compared to completely coplanar stacks. However, $\pi$-stacking interaction occurs between the thiophene and phenyl units in the neighboring stacks and their overlap is expected to be larger in TR1 than in TR2 (see Figure 3, left), assuming that the geometry is otherwise similar.

\begin{abstract}
Alternatively, we propose the neighboring stacks to have opposite roll directions for the TR2 structure to account for the observed "double period" in the $b$-direction. Thus, the thiophene/phenyl tails would assume a herringbone motif. We note that neither proposed structure has an effective $\pi$-stacking of the DPP groups.
\end{abstract}




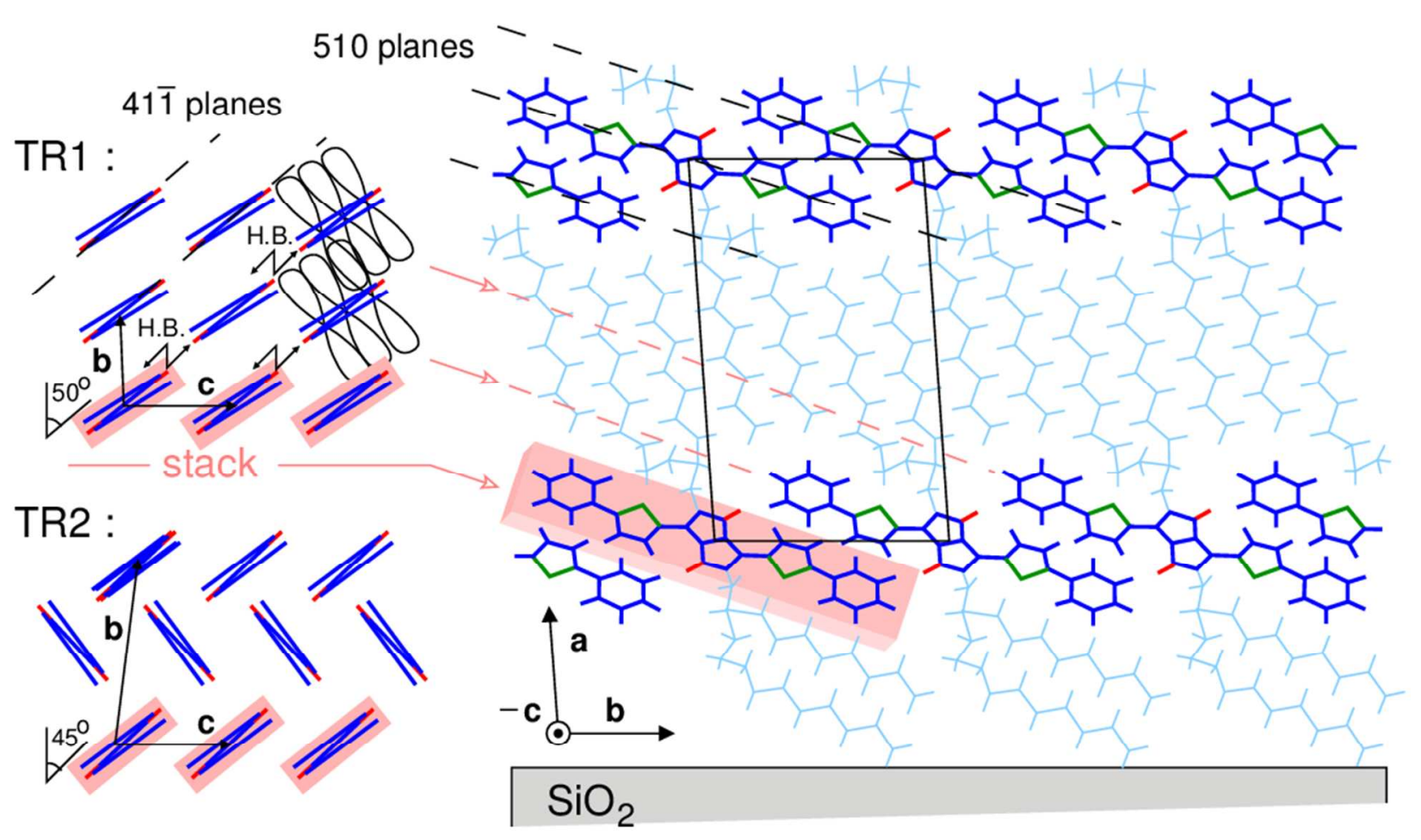

Figure 3. The proposed packing motif of the Ph-TDPP-Ph crystal structures TR1 and TR2. The view on the right is along the $c$-axis and molecules on a single stack are highlighted in pink (main group only). The image on the left shows a view along the molecule long axis. H.B. denotes hydrogen bonding between carbonyl oxygen. The orientation of side group alkyl chains, depicted by the curved lines, may be either perpendicular to the surface or along the molecule long axis. The drawing with respect to side groups is schematic. Dashed lines indicate some of the strongest scattering planes.

\subsection{GIXRD from Evaporated Films}

In order to test the structural integrity of $\mathrm{Ph}-\mathrm{TDPP}-\mathrm{Ph}$ based on the film deposition conditions, GIXRD measurements were conducted from evaporated films, which varied in thickness. All evaporated Ph-TDPP-Ph films show similar diffraction patterns as dropcast films. The GIXRD data from evaporated films of two different thicknesses are shown in Figure S5. A comparison with Figure 2 (a) shows additional features, most notably at $q_{h}=1.351 / \AA$. These patterns agree 
with the TR2 reflections and we thus conclude that both phases TR1 and TR2 are observed in these evaporated films.

Figure 4 shows the intensity profile along the $q_{h}=0.51 / \AA$ layer line for the evaporated samples compared with the dropcast films. The contribution from TR1 phase (red) and TR2 phase (blue) are superposed in the evaporated films. The ratio of TR1:TR2 is estimated from the ratio of the integrals of the two phases on this layer line. We also note that the vertical width of the reflections for both phases agrees with the nominal film thickness, so that the film consists of patches of the two phases. Evaporated films with thicknesses of $8 \mathrm{~nm}, 15 \mathrm{~nm}$, and $24 \mathrm{~nm}$ corresponded to TR1:TR2 ratios of 20:80, 65:35, and 55:45, respectively. For evaporated films, the peak broadening scales as $q^{2}$, which points to paracrystal lattice imperfections. The same is not observed for dropcast films.

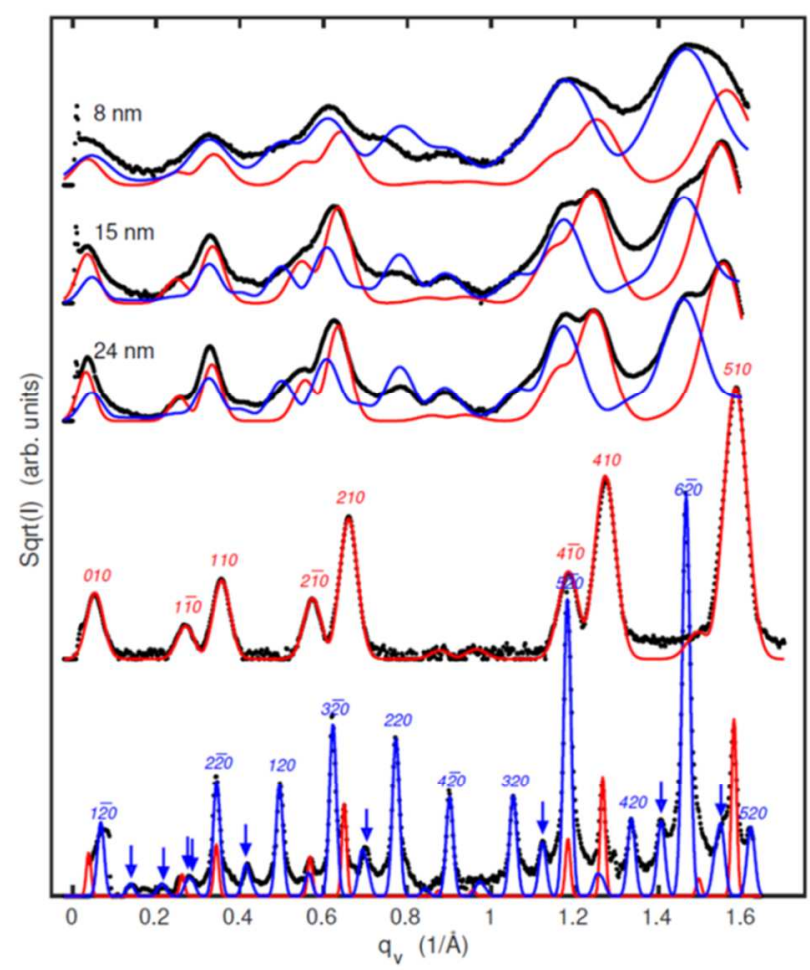

Figure 4. Black dots show the GIXRD intensity profiles along the $q_{h}=0.51 / \AA$ layer line for the evaporated samples with increasing thickness (top three curves) compared with the thin and thick 
dropcast films (two bottom curves). The two bottom curves correspond to the data shown in Figure 2 (a) and Figure S4, respectively. Fits to the TR1 phase are shown in red and the fits to the TR2 phase in blue.

Overall, the GIXRD results show similar structural properties from both evaporated and solution processed films. For some evaporated films, as discussed later in Section 3.3, the TR1 phase was the dominant phase. Solvents play some role in controlling the TR1:TR2 phase. The solvent mixture, DCB:Chl, yields films with a low fraction of the TR2 phase and for some cases, the TR2 phase was seen to be negligible. In order to correlate these structural properties, in particular the TR1:TR2 phase ratio to transport properties, FETs were fabricated from both evaporated and dropcast Ph-TDPP-Ph films, identical to what was used for GIXRD.

\subsection{FET Characteristics}

The schematic architectures of the FETs are shown in Figure 1. The bottom-contact geometry, as seen in Figure 1 (d), allows a close fit for electrical connections during GIXRD measurements. The light molecular weight of these small molecules allows thermal evaporation deposition with finely controlled film thicknesses. Evaporated films ranged from $8 \mathrm{~nm}-30 \mathrm{~nm}$ in thickness while dropcast films ranged from $50-200 \mathrm{~nm}$ in separate devices. The FET characteristics were obtained for varying thicknesses of the evaporated Ph-TDPP-Ph films. $P$ type carrier mobilities were obtained using $\mu=\frac{2}{C_{i}} \frac{L}{W}\left(\frac{\partial \sqrt{I_{D S}}}{\partial V_{G}}\right)^{2}$, where $C_{\mathrm{i}}$ is the dielectric capacitance, $L$ is the channel length, $W$ is the channel width, $I_{D S}$ is the drain current, and $V_{G}$ is the gate voltage. For transfer properties, the gate voltage is swept up to the constantly applied drain voltage, $V_{D S}$, which is in the saturation region. A linear fit of this saturation region can then be used to obtain the carrier mobilities for a given FET. An example of obtaining the carrier mobility in the linear region of the output characteristics is shown in the Supporting Information. 
Figures 5 (a) and (b) show the output and transfer characteristics from a top-contact (with bottom $\mathrm{SiO}_{2}$ gate insulator) FET with evaporated Ph-TDPP-Ph film of thickness $12 \mathrm{~nm}$. Although GIXRD was not directly measured from this particular device, similar films were identified as being only the TR1 phase, where good transport properties are expected. The hole mobility for these Ph-TDPP-Ph FETs are as high as $0.1 \mathrm{~cm}^{2} / \mathrm{Vs}$ with $\mathrm{I}_{\text {on }} / \mathrm{I}_{\text {off }}$ as $10^{6}$ and a threshold voltage, $V_{T h}$, of $-10.1 \mathrm{~V}$ (Figure 5 (b)). Next, we compare the FET properties from films with known TR1:TR2 phase ratios and different film processing conditions.

The dropcast films were deposited on $\mathrm{SiO}_{2}$ as discussed in Section 2.4. Although solvent-vapor annealing produces thin crystallites, getting a uniform coverage over the FET channel length and width dimensions can be challenging. Thus, the dropcast films used were annealed without any solvent-vapor treatment. Figures 5 (c) and (d) display the output and transfer characteristics from a typical dropcast FET. These devices were fabricated as top-contact, bottom-gate and all the FETs perform in a similar fashion. The inset of Figure 5 (d) shows an optical image of a dropcast $\mathrm{Ph}$-TDPP-Ph film with a uniform coverage on a substrate that supports four different FETs. The thickness of the dropcast film across the active area was roughly $50 \mathrm{~nm}$. The $\mathrm{I}_{\mathrm{on}} / \mathrm{I}_{\text {off }}$ ratio and the hole mobility are $\sim 10^{3}$ and $7 \times 10^{-4} \mathrm{~cm}^{2} / \mathrm{Vs}$, respectively. The top-contact FET geometry for both evaporated and spincoated Ph-TDPP-Ph films perform better compared to the bottom-contact FETs. Unlike the bottom-contact geometries, the FETs switch on at a much lower voltage in top-contact FETs; the threshold voltage in Figure 5 (d) is -6 V. For this dropcast film, a DCB:Chl solvent was used. These dropcast Ph-TDPP-Ph films have shown roughly a 20:1 TR1 to TR2 phase ratio. It can start to be seen that when both monomer phases are present, the FET device performances are significantly diminished compared to when only the TR1 phase is present. In 
order to understand the role of the two phases on charge transport, additional FETs were fabricated to directly compare phase ratios among evaporated films.
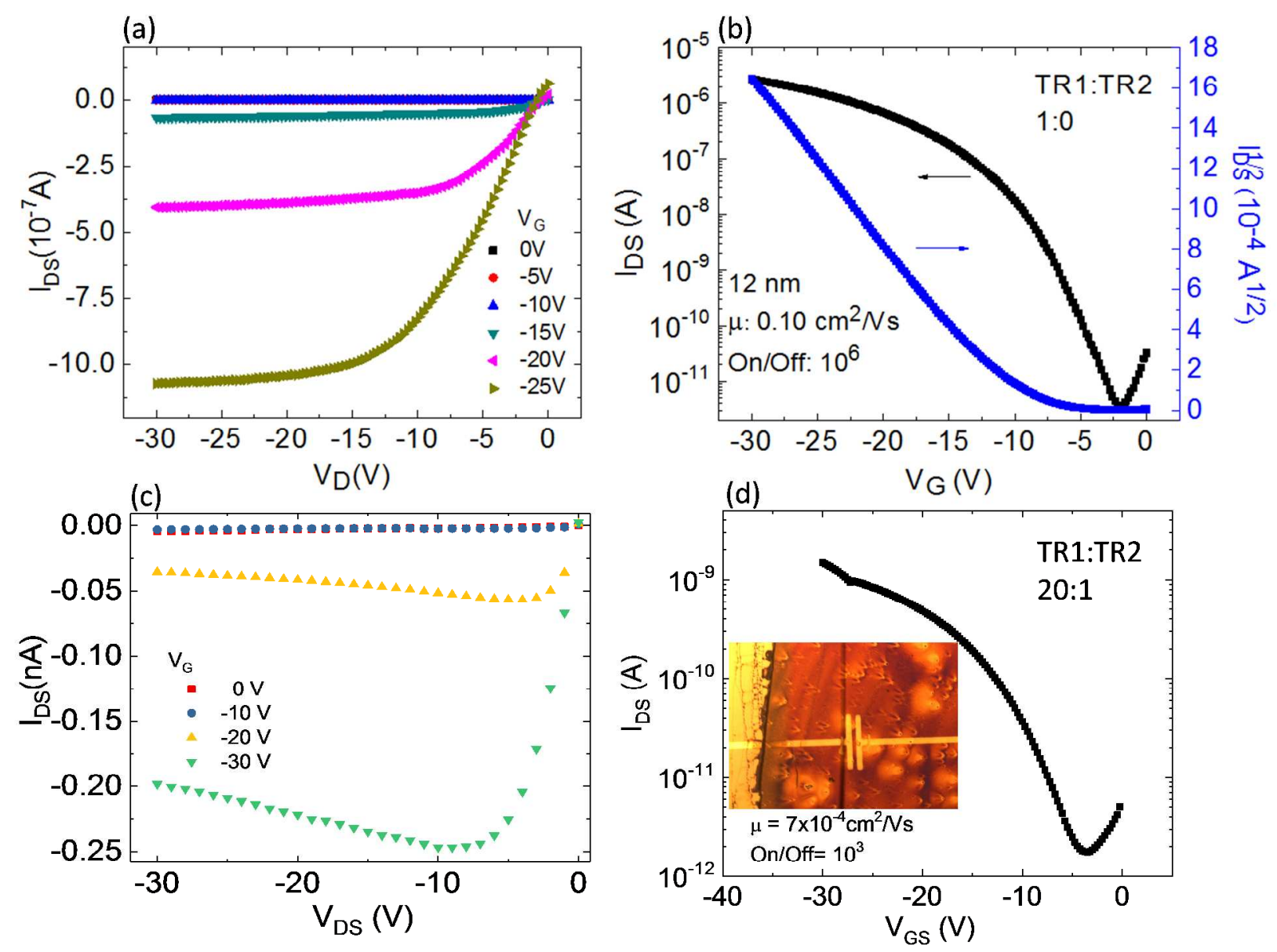

Figure 5. (a) Output and (b) transfer characteristics from a Ph-TDPP-Ph evaporated FET (12 nm film). This film is of only the TR1 phase. (c) Output and (d) transfer characteristics from a PhTDPP-Ph dropcast top-contact, bottom-gated FET. The inset in (d) shows an optical image of the film and the device. The channel length (separation between the two Au vertical lines) is 200 $\mu \mathrm{m}$.

The evaporated films were deposited onto $\mathrm{SiO}_{2}$ gate dielectric in a top-contact, bottom-gate device architecture with varied thickness ranging from $8 \mathrm{~nm}$ to $30 \mathrm{~nm}$. Figure 6 displays the transfer characteristics for evaporated films of thicknesses $8 \mathrm{~nm}$ and $24 \mathrm{~nm}$ (whose GIXRD data 
is shown in the Supporting Information, Figure S5). As suggested with the dropcast film, when the TR2 phase is present, the carrier mobility is significantly reduced. Indeed, we continue to see that trend in these evaporated films. When considering average values taken across all devices per film thickness and substrate (Table 1), we observe that an increasing percentage of the TR2 phase present in the film leads to decreasing hole mobilities, $\mathrm{I}_{\mathrm{On}} / \mathrm{I}_{\mathrm{Off}}$, and increasing threshold voltages. Table 1 shows the average values of FET performance for at least 10 devices for each of the evaporated Ph-TDPP-Ph film thicknesses. The decrease in FET performance with increasing TR2 phase may be attributed to the differences in molecular packing - coplanar vs. herringbone packing motif - of neighboring stacks. Both TR1 and TR2 phases are found to have a large rotation around the molecule long axis $\left(\sim 45-55^{\circ}\right)$ so there is no overlap of the $\pi$ orbitals within the stacks in either phase. However, the coplanar configuration allows an overlap between the molecules in neighboring stacks, whereas the herringbone motif inhibits such an overlap. This is in contrast with the more general case such as in pentacene where enhanced carrier transport arises due to an overlap within the stacks and is significant even in herringbone packing. ${ }^{32}$ It is also important to note that varying the film thickness does not necessarily dictate the TR1:TR2 phase ratio, as separate substrates with the same film thickness can have quite different electrical properties, indicating different phase ratios (Figure S6). In addition, OTS and non-OTS treated $\mathrm{SiO}_{2}$ substrates with evaporated films show similar FET performances (Figure S7). Although the exact thermodynamic barrier and the kinetics that govern the two proposed phases are not known, we see a clear correlation in degradation of charge transport with an increase in the TR2 phase. 


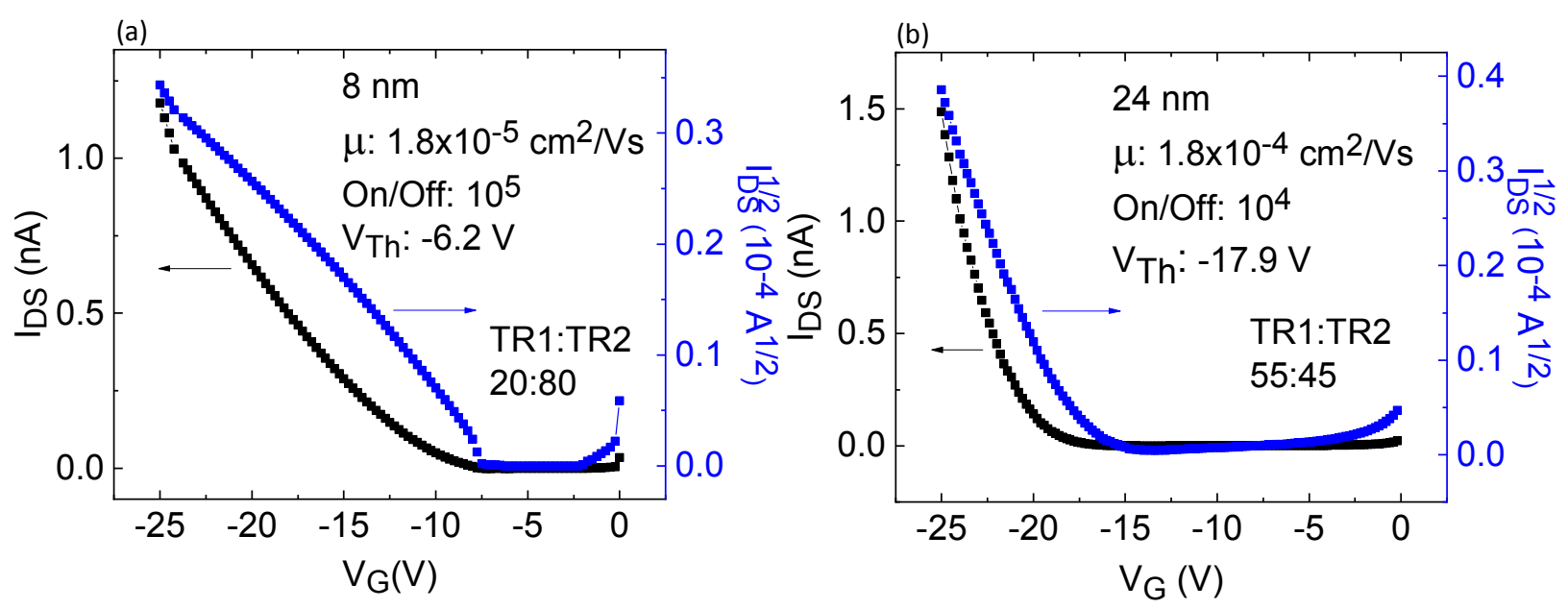

Figure 6. Transfer characteristics for (a) $8 \mathrm{~nm}$ and (b) $24 \mathrm{~nm}$ evaporated films from top-contact FETs. Text insets display quantities for a single, typical device. Presence of the TR2 phase decreases electrical conductivity, which is evident in the decreasing hole mobility.

Table 1. Best and average values of FET performances for various thicknesses and TR1:TR2 phase ratios for selected evaporated films in top-contact geometry. Per film thickness, averages were taken across several FETs on the same substrate (up to 20 available). Electrical characteristics are best when the film is dominated by TR1, and decrease for increasing percentage of TR2 phase.

\begin{tabular}{cccc}
\hline Film Thickness $(\mathrm{nm})$ & 8 & 24 & 12 \\
\hline TR1:TR2 Ratio & $20: 80$ & $55: 45$ & $100: 0$ \\
Hole Mobility, Best $\left(\mathrm{cm}^{2} / \mathrm{Vs}\right)$ & $2.8 \times 10^{-5}$ & $1.8 \times 10^{-4}$ & 0.10 \\
Hole Mobility, Average $\left(\mathrm{cm}^{2} / \mathrm{Vs}\right)$ & $1.6 \times 10^{-5}$ & $1.0 \times 10^{-4}$ & $6.2 \times 10^{-2}$ \\
On/Off Ratio, Average & $1 \times 10^{4}$ & $4 \times 10^{4}$ & $1 \times 10^{6}$ \\
Threshold Voltage, Average (V) & -9.6 & -9.1 & -8.5 \\
\hline
\end{tabular}




\subsection{In-Operando GIXRD on FETs}

Another interesting component of this film structure, and thus the charge transfer mechanism, is determining how stable the film structure is while the FET is operating. When molecules within a film are subject to rotating or shifting in the presence of an electric field, charge transfer properties are affected. The work done by Liscio et al. shows that a pentacene film structure changes during FET operation, sweeping up to $\mathrm{V}_{\mathrm{G}}=\mathrm{V}_{\mathrm{DS}}=-30 \mathrm{~V} .^{30}$ To better understand the PhTDPP-Ph monomer studied here, GIXRD measurements were conducted in-operando for multiple film thicknesses that were evaporated. The GIXRD measurements were obtained from the bottom-gate, bottom-contact FETs (Figure 1 (d)) by biasing the FETs in the saturation region and for a few values of $\mathrm{V}_{\mathrm{G}}$.

Figure 7 (a) shows the transfer curves from two bottom-contact FETs with different TR1:TR2 concentrations. As stated earlier, the bottom contact devices perform worse than the top-contact devices. For the same device architecture (W/L ratios) the overall current decreases with an increase in the TR2 phase similar to what is seen in the top-contact devices with both dropcast and evaporated films. The carrier mobilities of the $15 \mathrm{~nm}$ and $24 \mathrm{~nm}$ film FETs are $1 \times 10^{-4}$ $\mathrm{cm}^{2} / \mathrm{Vs}$ and $5 \times 10^{-5} \mathrm{~cm}^{2} / \mathrm{Vs}$, respectively. As noted earlier the TR1:TR2 phase ratio is $65: 35$ and 55:45 for the $15 \mathrm{~nm}$ and $24 \mathrm{~nm}$ film thicknesses, respectively.

Figure 7 (b) and (c) compares the GIXRD patterns obtained for a $15 \mathrm{~nm}$ evaporated film with and without electrical bias. Both the TR1 and TR2 reflections (indicated by red and blue labels, respectively) are observed. We observe no change in the film structure during FET operation, where voltages were swept up to $\mathrm{V}_{\mathrm{G}}=-50 \mathrm{~V}$ and $\mathrm{V}_{\mathrm{DS}}=-30 \mathrm{~V}$. The biased pattern displays more indexed reflections only due to the difference in peak contrast. Both patterns show identical reflection peak positions. The GIXRD measurements were conducted over an hour by applying 
the bias voltage. These results show that any instability that may arise due to a bias-stress (see Fig. S9) has no origin in structural changes.
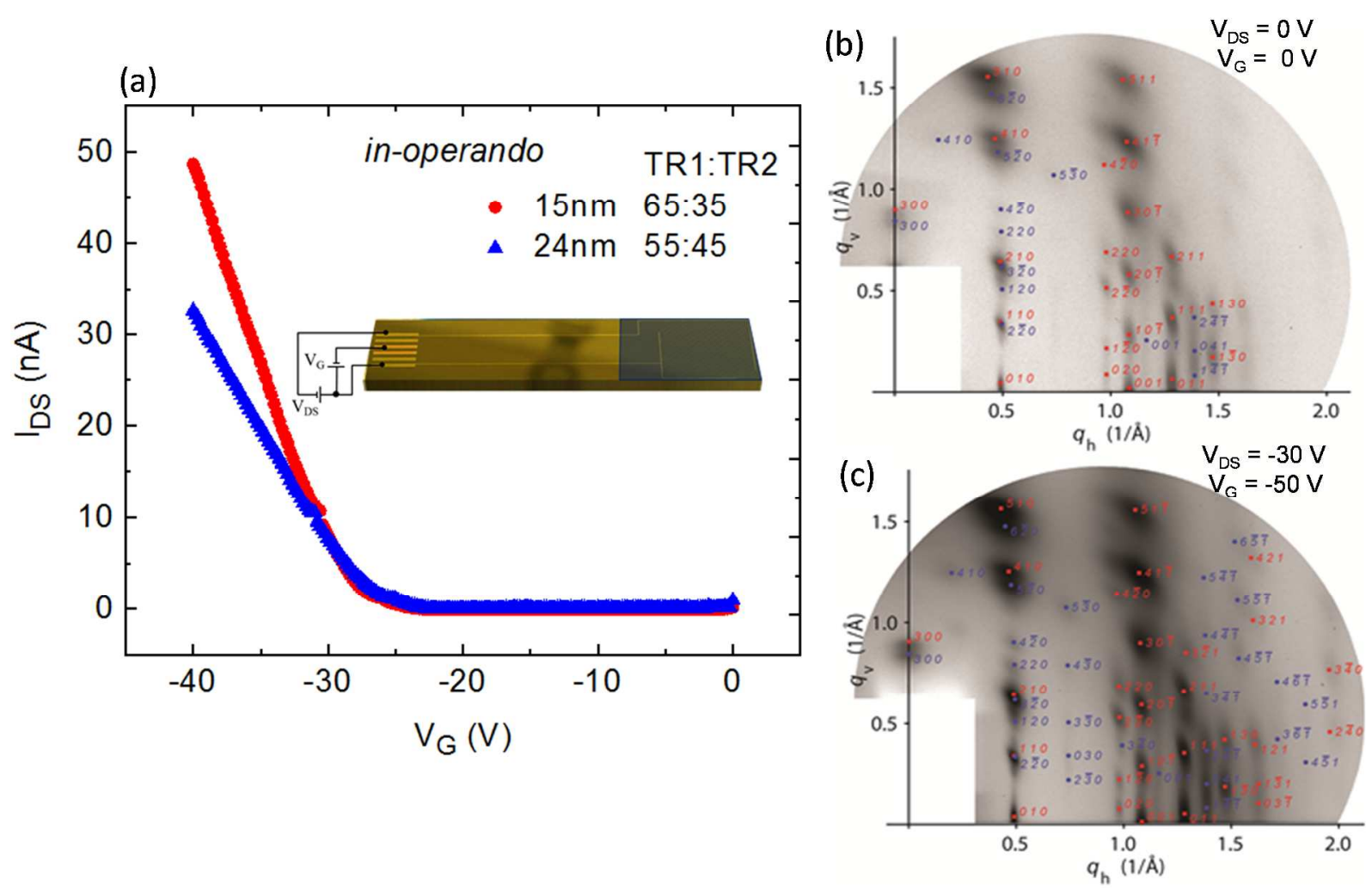

Figure 7. (a) Transfer curves of evaporated films for film thicknesses of $15 \mathrm{~nm}$ and $24 \mathrm{~nm}$ in a bottom-contact, bottom-gate FET architecture. The inset shows an image of the FET. As compared to the top-contact devices, the hole mobilities and On/Off currents are lower. GIXRD patterns for an evaporated $15 \mathrm{~nm}$ film (b) with and (c) without electrical bias. The film structure remains unchanged under an applied bias. Reflections from TR1 and TR2 are marked by red and blue.

\section{CONCLUSIONS}

In summary, GIXRD studies from n-dialkyl side-chain substituted DPP monomer reveal a triclinic crystal structure with two phase polymorphism (TR1 and TR2) and the $\pi$-conjugated 
stacking direction oriented in-plane. The two phases are seen in both evaporated and solution processed films. Although a direct correlation between the ratio of the phases and the processing condition could not be ascertained, solvents such as dichlorobenzene and chloroform result in a higher fraction of the TR1 phase over TR2 compared to solvents such as toluene. $\pi$-stacking interaction occurs between the thiophene and phenyl units in the neighboring stacks and their overlap is expected to be larger in TR1 compared to the TR2 phase. The thiophene and phenyl tails in the TR2 phase assume a herringbone motif, which deviates from the coplanar orientation of the TR1 phase, and thus inhibits charge transport.

A one-to-one correlation with FET device performance for different TR1:TR2 phase ratios along with the GIXRD results clearly show that the FET carrier mobilities may change by two to three orders of magnitude as the ratio decreases. A decreasing percentage of the TR2 phase in thin films improves charge transport and consequently FET performance. Future directions will entail solvent annealing conditions to understand if a better control over obtaining the all TR1 phase, both in evaporated and dropcast films, is feasible. The existence of multiple crystal structures or polymorphs, as seen in this work, may be generic to other DPP oligomers and polymers, and could thus be responsible for variations in transport properties in FETs and photodiodes. A chain length dependence of Ph-TDPP-Ph oligomers up to five repeating units shows decreased crystallinity and $d$ spacing with increasing units, which has been attributed to a change in stacking due to conformational disorders. ${ }^{15}$ However, thus far there are no studies on the existence of polymorphs with increasing chain length. It is feasible that polymorphs may have an origin in the imperfect stacking with increased chain length. Correlating structure with transport studies of Ph-TDPP-Ph oligomers with well-defined chain lengths using high resolution GIXRD could help understand the connection between intermolecular electronic coupling and 
structural order. Such studies in the future will pave the way for design rules for DPP oligomers and polymers for improved carrier transport in electronic devices.

GIXRD from in-operando FETs is a unique way of obtaining not just the structural information but also structural changes, if any, under applied electric fields. GIXRD studies were conducted in-operando from Ph-TDPP-Ph FETs for different film thicknesses under an applied bias. The reflection peak positions of the TR1 and TR2 phases remain unchanged for pristine films versus biased devices. These results further suggest that the variations in FET performance originate from the ratio of the TR1 and TR2 phases and not any structural changes upon device operation.

\begin{abstract}
ASSOCIATED CONTENT
Supporting Information

NMR/MALDI characterization of Ph-DPP-Ph and additional electrical characterization and GIXRD data. This material is available free of charge via the Internet at http://pubs.acs.org.
\end{abstract}

\title{
AUTHOR INFORMATION
}

\section{Corresponding Author}

*guhas@missouri.edu

\$matti.knaapila@fysik.dtu.dk 


\section{Author Contributions}

The manuscript was written through contributions of all authors. All authors have given approval to the final version of the manuscript.

\section{ACKNOWLEDGMENT}

We acknowledge the support of this work through the U.S. National Science Foundation under Grant No. ECCS-1707588. DTU authors thank DANSCATT, the Danish Council for Independent Research (Grant ID 6111-00140) and MAX4ESSFUN of the European Regional Development Fund Interreg Öresund-Kattegat-Skagerrak (project DTU-038) for financial support. S.P. would like to acknowledge funding received from Swarnajayanti fellowship. T.M. would like to thank IISc for senior research fellowship. We thank the beamline scientists at XMaS.

\section{REFERENCES}

1. Kanimozhi, C.; Yaacobi-Gross, N.; Chou, K. W.; Amassian, A.; Anthopoulos, T. D.; Patil, S. Diketopyrrolopyrrole-Diketopyrrolopyrrole-Based Conjugated Copolymer for HighMobility Organic Field-Effect Transistors. J. Am. Chem. Soc 2012, 134, 16532-16535.

2. Li, J.; Zhao, Y.; Tan, H. S.; Guo, Y.; Di, C.-A.; Yu, G.; Liu, Y.; Lin, M.; Lim, S. H.; Zhou, Y.; Su, H.; Ong, B. S. A Stable Solution-Processed Polymer Semiconductor with Record High-Mobility for Printed Transistors. Sci. Rep. 2012, 2, 754.

3. Senanayak, S. P.; Ashar, A. Z.; Kanimozhi, C.; Patil, S.; Narayan, K. S. RoomTemperature Bandlike Transport and Hall Effect in a High-Mobility Ambipolar Polymer. Phys. Rev. B 2015, $91,115302$.

4. Sonar, P.; Singh, S. P.; Li, Y.; Soh, M. S.; Dodabalapur, A. A Low-Bandgap Diketopyrrolopyrrole-Benzothiadiazole-Based Copolymer for High-Mobility Ambipolar Organic Thin-Film Transistors. Adv. Mater. 2010, 22, 5409-5413.

5. Zhang, Y.; Kim, C.; Lin, J.; Nguyen, T.-Q. Solution-Processed Ambipolar Field-Effect Transistor Based on Diketopyrrolopyrrole Functionalized with Benzothiadiazole. Adv. Funct. Mater. 2012, 22, 97-105. 
6. Adil, D.; Kanimozhi, C.; Ukah, N.; Paudel, K.; Patil, S.; Guha, S. Electrical and Optical Properties of Diketopyrrolopyrrole-Based Copolymer Interfaces in Thin Film Devices. ACS Appl. Mater. Interfaces 2011, 3, 1463-1471.

7. Mukhopadhyay, T.; Puttaraju, B.; Senanayak, S. P.; Sadhanala, A.; Friend, R.; Faber, H. A.; Anthopoulos, T. D.; Salzner, U.; Meyer, A.; Patil, S. Air-Stable N-Channel Diketopyrrolopyrrole-Diketopyrrolopyrrole Oligomers for High Performance Ambipolar Organic Transistors. ACS Appl. Mater. Interfaces 2016, 8, 25415-25427.

8. $\quad$ Liu, J.; Sun, Y.; Moonsin, P.; Kuik, M.; Proctor, C. M.; Lin, J.; Hsu, B. B.; Promarak, V.; Heeger, A. J.; Nguyen, T.-Q. Tri-Diketopyrrolopyrrole Molecular Donor Materials for HighPerformance Solution-Processed Bulk Heterojunction Solar Cells. Adv. Mater. 2013, 25, 58985903.

9. $\quad$ Chen, B.; Yang, Y.; Cheng, P.; Chen, X.; Zhan, X.; Qin, J. Designing a Thiophene-Fused Dpp Unit to Build an a-D-a Molecule for Solution-Processed Solar Cells. J. Mater. Chem. A 2015, 3, 6894-6900.

10. Naik, M. A.; Patil, S. Diketopyrrolopyrrole-Based Conjugated Polymers and Small Molecules for Organic Ambipolar Transistors and Solar Cells. J. Polym. Sci. A 2013, 51, 42414260 .

11. Pickett, A.; Mohapatra, A.; Laudari, A.; Khanra, S.; Ram, T.; Patil, S.; Guha, S. Hybrid Zno-Organic Semiconductor Interfaces in Photodetectors: A Comparison of Two near-Infrared Donor-Acceptor Copolymers. Org. Electron. 2017, 45, 115-123.

12. Kanimozhi, C.; Naik, M.; Yaacobi-Gross, N.; Burnett, E. K.; Briseno, A. L.; Anthopoulos, T. D.; Patil, S. Controlling Conformations of Diketopyrrolopyrrole-Based Conjugated Polymers: Role of Torsional Angle. J. Phys. Chem. C 2014, 118, 11536-11544.

13. Lee, O. P.; Yiu, A. T.; Beaujuge, P. M.; Woo, C. H.; Holcombe, T. W.; Millstone, J. E.; Douglas, J. D.; Chen, M. S.; Fréchet, J. M. J. Efficient Small Molecule Bulk Heterojunction Solar Cells with High Fill Factors Via Pyrene-Directed Molecular Self-Assembly. Adv. Mater. 2011, 23, 5359-5363.

14. Goswami, S.; Hernandez, J. L.; Gish, M. K.; Wang, J.; Kim, B.; Laudari, A. P.; Guha, S.; Papanikolas, J. M.; Reynolds, J. R.; Schanze, K. S. Cyclometalated Platinum-Containing Diketopyrrolopyrrole Complexes and Polymers: Photophysics and Photovoltaic Applications. Chem. Mater. 2017, 29, 8449-8461.

15. Mukhopadhyay, T.; Puttaraju, B.; Roy, P.; Dasgupta, J.; Meyer, A.; Rudnick, A.; Tscheuschner, S.; Kahle, F.-J.; Köhler, A.; Patil, S. Facile Synthesis and Chain-Length Dependence of the Optical and Structural Properties of Diketopyrrolopyrrole-Based Oligomers. Chem. Eur. J. 2017, 23, 13718-13723.

16. Diemer, P. J.; Lyle, C. R.; Mei, Y.; Sutton, C.; Payne, M. M.; Anthony, J. E.; Coropceanu, V.; Brédas, J.-L.; Jurchescu, O. D. Vibration-Assisted Crystallization Improves Organic/Dielectric Interface in Organic Thin-Film Transistors. Adv. Mater. 2013, 25, 6956-6962.

17. Ward, J. W.; Loth, M. A.; Kline, R. J.; Coll, M.; Ocal, C.; Anthony, J. E.; Jurchescu, O. D. Tailored Interfaces for Self-Patterning Organic Thin-Film Transistors. J. Mater. Chem. 2012, 22, 19047-19053.

18. Jones, A. O. F.; Chattopadhyay, B.; Geerts, Y. H.; Resel, R. Substrate-Induced and ThinFilm Phases: Polymorphism of Organic Materials on Surfaces. Adv. Funct. Mater. 2016, 26, 2233-2255.

19. Chung, H.; Diao, Y. Polymorphism as an Emerging Design Strategy for High Performance Organic Electronics. J. Mater. Chem. C 2016, 4, 3915-3933. 
20. Thankaraj Salammal, S.; Zhang, Z.; Chen, J.; Chattopadhyay, B.; Wu, J.; Fu, L.; Fan, C.; Chen, H. Polymorphic Phase-Dependent Optical and Electrical Properties of a Diketopyrrolopyrrole-Based Small Molecule. ACS Appl. Mater. Interfaces 2016, 8, 2091620927.

21. Salammal, S. T.; Balandier, J.-Y.; Arlin, J.-B.; Olivier, Y.; Lemaur, V.; Wang, L.; Beljonne, D.; Cornil, J.; Kennedy, A. R.; Geerts, Y. H.; Chattopadhyay, B. Polymorphism in Bulk and Thin Films: The Curious Case of Dithiophene-Dpp(Boc)-Dithiophene. J. Phys. Chem. C 2014, 118, 657-669.

22. Hailey, A. K.; Petty, A. J.; Washbourne, J.; Thorley, K. J.; Parkin, S. R.; Anthony, J. E.; Loo, Y.-L. Understanding the Crystal Packing and Organic Thin-Film Transistor Performance in Isomeric Guest-Host Systems. Adv. Mater. 2017, 29, 1700048-n/a.

23. Thorley, K. J.; Finn, T. W.; Jarolimek, K.; Anthony, J. E.; Risko, C. Theory-Driven Insight into the Crystal Packing of Trialkylsilylethynyl Pentacenes. Chem. Mater. 2017, 29, 2502-2512.

24. Stevens, L. A.; Goetz, K. P.; Fonari, A.; Shu, Y.; Williamson, R. M.; Brédas, J.-L.; Coropceanu, V.; Jurchescu, O. D.; Collis, G. E. Temperature-Mediated Polymorphism in Molecular Crystals: The Impact on Crystal Packing and Charge Transport. Chem. Mater. 2015, 27, $112-118$

25. Tello, M.; Chiesa, M.; Duffy, C. M.; Sirringhaus, H. Charge Trapping in Intergrain Regions of Pentacene Thin Film Transistors. Adv. Funct. Mater. 2008, 18, 3907-3913.

26. Häusermann, R.; Batlogg, B. Gate Bias Stress in Pentacene Field-Effect-Transistors: Charge Trapping in the Dielectric or Semiconductor. Appl. Phys. Lett. 2011, 99, 083303.

27. Mathijssen, S. G. J.; Spijkman, M.-J.; Andringa, A.-M.; van Hal, P. A.; McCulloch, I.; Kemerink, M.; Janssen, R. A. J.; de Leeuw, D. M. Revealing Buried Interfaces to Understand the Origins of Threshold Voltage Shifts in Organic Field-Effect Transistors. Adv. Mater. 2010, 22, 5105-5109.

28. Adil, D.; Guha, S. Surface-Enhanced Raman Spectroscopic Studies of MetalSemiconductor Interfaces in Organic Field-Effect Transistors. J. Phys. Chem. C 2012, 116, 12779-12785.

29. Adil, D.; Guha, S. Surface-Enhanced Raman Spectroscopic Studies of the Au-Pentacene Interface: A Combined Experimental and Theoretical Investigation. J. Chem. Phys. 2013, 139, 044715 .

30. $\quad$ Liscio, F.; Ferlauto, L.; Matta, M.; Pfattner, R.; Murgia, M.; Rovira, C.; Mas-Torrent, M.; Zerbetto, F.; Milita, S.; Biscarini, F. Changes of the Molecular Structure in Organic Thin Film Transistors During Operation. J. Phys. Chem. C 2015, 119, 15912-15918.

31. Huss-Hansen, M. K.; Lauritzen, A. E.; Bikondoa, O.; Torkkeli, M.; Tavares, L.; Knaapila, M.; Kjelstrup-Hansen, J. Structural Stability of Naphthyl End-Capped Oligothiophenes in Organic Field-Effect Transistors Measured by Grazing-Incidence X-Ray Diffraction in Operando. Org. Electron. 2017, 49, 375-381.

32. Curtis, M. D.; Cao, J.; Kampf, J. W. Solid-State Packing of Conjugated Oligomers: From $\Pi$-Stacks to the Herringbone Structure. J. Am. Chem. Soc 2004, 126, 4318-4328.

33. Hartnett, P. E.; Margulies, E. A.; Mauck, C. M.; Miller, S. A.; Wu, Y.; Wu, Y.-L.; Marks, T. J.; Wasielewski, M. R. Effects of Crystal Morphology on Singlet Exciton Fission in Diketopyrrolopyrrole Thin Films. J. Phys. Chem. B 2016, 120, 1357-1366. 
Table of Contents Graphic and Synopsis
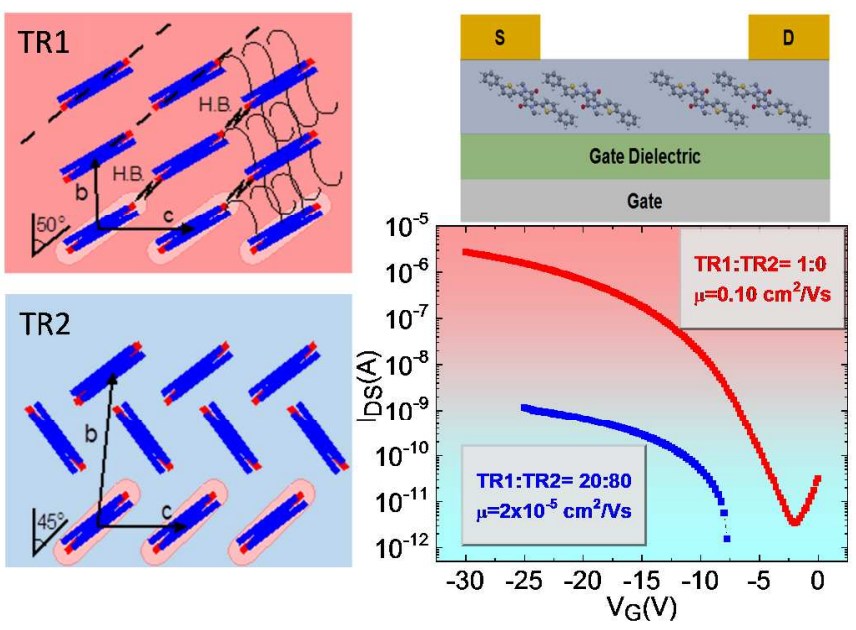